\title{
ARTICLES
}

\section{PREPARE TO RELAX: JACOBSON'S PROGRESSIVE RELAXATION TECHNIQUE}

Israel Jeba Prabu, D. * | Dr. C.P. Sharma **

* Research Scholar, Bee Enn College of Nursing, Chak Bhalwal, Jammu \& Kashmir, India. ** Guide and Associate Professor, Himalayan University, Itanagar, Arunachal Pradesh, India. DOI: http://doi.org/10.47211/idcij.2020.v07i03.004

Received $25^{\text {th }}$ May 2020, Accepted $5^{\text {th }}$ June 2020, Available online $10^{\text {th }}$ July 2020.

\section{"Health and well-being is a duty, otherwise we shall not be able to keep our mind strong and clear."}

Buddha

\section{ABSTRACT}

The aim of this information sheet is to remind you about how you can manage your stress using Jacobson's progressive relaxation technique. This is a technique that uses muscle contraction and relaxation to make you feel calmer. Jacobson's Progressive muscle relaxation is an exercise that relaxes your mind and body by progressively tensing and relaxing muscle groups throughout your entire body. You will tense each muscle group vigorously, but without straining, and then suddenly release the tension and feel the muscle relax. You will tense each muscle for about 5 seconds. If you have any pain or discomfort at any of the targeted muscle groups feel free to omit that step. Throughout this exercise you may visualise the muscles tensing and a wave of relaxation flowing over them as you release that tension. It is important that you keep breathing throughout the exercise.

Key Words: Jacobson's Progressive muscle relaxation, relaxation and exercise.

\section{About Authors}

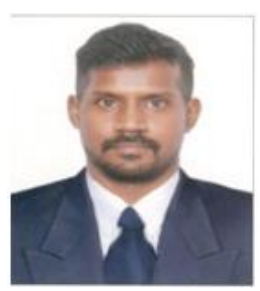

Author Mr. Israel Jeba Prabu, D. is working as an Assistant Professor in Bee Enn college of Nursing, Chak Bhalwal, Jammu \& Kashmir, India.

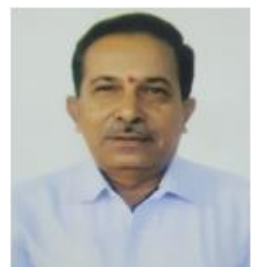

Author Dr. C.P. Sharma is Associate Professor in Himalayan University at Itanagar, Arunachal Pradesh. He is Research guide for PG and PhD Scholars. He had organised various conferences, seminars and workshop at national and state levels. 


\section{INTRODUCTION}

Dr. Edmund Jacobson invented the technique in the 1920s as a way to help his patients deal with anxiety. Dr. Jacobson felt that relaxing the muscles could relax the mind as well. The technique involves tightening one muscle group while keeping the rest of the body relaxed, and then releasing the tension.

Relaxation techniques are very useful in dealing with depression, anxiety and stress by dealing with mind body healing. Relaxation techniques help in reducing physical and mental stresses. Most patients require training to understand how to reduce depression. Among the relaxation a technique, Jacobson's Progressive Muscle Relaxation Technique (JPMRT) is a non-pharmacological, complementary therapy, easy to learn; can be performed without assistance, less expensive and with no side effects.

Progressive muscle relaxation is one of the most commonly used relaxation techniques. Jacobson's relaxation technique is a type of therapy that focuses on tightening and relaxing specific muscle groups in sequence. It is also known as progressive relaxation therapy. By concentrating on specific areas and tensing and then relaxing them, you can become more aware of your body and physical sensations.

\section{A MULTITUDE OF POSSIBLE HEALTH BENEFITS}

Have you ever had an aching back or pain in your neck when you were anxious or stressed? When you have anxiety or stress in your life, one of the ways your body responds is with muscle tension. Progressive muscle relaxation is a method that helps relieve that tension.

* In progressive muscle relaxation, you tense a group of muscles as you breathe in, and you relax them as you breathe out. You work on your muscle groups in a certain order.

* When your body is physically relaxed, you cannot feel anxious. Practising progressive muscle relaxation for a few weeks will help you get better at this skill, and in time you will be able to use this method to relieve stress.

* When you first start, it may help to use an audio recording until you learn all the muscle groups in order. Check your local library or a bookstore for progressive muscle relaxation audio recordings.

* If you have trouble falling asleep, this method may also help with your sleep problems.

Practicing relaxation techniques can have a variety of health benefits, such as:

- relieving anxiety

- $\quad$ reducing work-related stress

- lowering your blood pressure

- reducing the likelihood of seizures

- improving your sleep

\section{WHAT IS THE PURPOSE OF THE TECHNIQUE?}

Relaxation can help to relieve the symptoms of stress. Although the cause of the anxiety will not disappear, you will probably feel more able to deal with it once you have released the tension in your body and cleared your thoughts. Jacobson's progressive relaxation technique involves contracting and relaxing the muscles to make you feel calmer. Do not worry if you find it difficult to relax at first. It is a skill that needs to be learned and it will come with practice. Once you have mastered it you will be able to use it throughout your life, for example while travelling, sitting in your office or standing in a supermarket queue.

\section{REQUIREMENTS OF JACOBSON'S PROGRESSIVE MUSCLE RELAXATION TECHNIQUE (JPMR) -}

Environment which is conducive: Allow yourself 15-20 minutes to complete this relaxation technique. Find a place that is warm, quiet and free from disturbances. If possible dim the lights and tell people that you should not be disturbed - you may want to switch off phones. Make yourself comfortable on the floor, on the bed or in a chair. Snuggle down and settle your body so that it feels limp.

General Instruction (Before and During Muscle Relaxation Exercise): This instruction is kept simple and is easily understood by students exposed to Jacobson's progressive muscle relaxation technique and gives them a clear picture of how to cooperate during the exercise regimen.

a) To sit on a chair as comfortable as possible. Keep your body loose, light and free.

b) Be calm and comfortable. 


\section{ARTICLES}

c) Keep your eyes closed.

d) Avoid stray thoughts.

e) Avoid extra movements of the body

f) During the part of the exercise cycle tense the muscle tightly and hold for slow count of 5 seconds. (Repeat silently 1001, 1002, 1003...)

g) During the relaxation part of the exercise cycle, it relaxes the muscle quickly and completely. Let your mind relax and appreciate how relaxed the muscle is feeling for 10 seconds.

h) Try to keep all other muscles relaxed as you exercise a specific muscle group.

i) As you exercise from head to toe, observe changes like tightness and the development of light and soothing sensations.

j) Relax by taking three deep breaths inhaling through nose and exhaling through mouth after each step.

k) Now make your body completely loose, light and free. Be aware of what it is like to feel relaxed.

\section{THE PROCEDURE}

You can use an audio recording to help you focus on each muscle group, or you can learn the order of muscle groups and do the exercises from memory. Choose a place where you will not be interrupted and where you can lie down on your back and stretch out comfortably, such as a carpeted floor.

1. Breathe in, and tense the first muscle group (hard but not to the point of pain or cramping) for 4 to 10 seconds.

2. Breathe out, and suddenly and completely relax the muscle group (do not relax it gradually).

3. Relax for 10 to 20 seconds before you work on the next muscle group. Notice the difference between how the muscles feel when they are tense and how they feel when they are relaxed.

4. When you are finished with all of the muscle groups, count backward from 5 to 1 to bring your focus back to the present.

After you have learned how to tense and relax each muscle group, here is something else to try. When you have a very tense muscle, you can practice tensing and relaxing that muscle area without going through the whole routine.

\section{Whole-body technique}

Joy Rains is the author of 'Meditation Illuminated: Simple Ways to Manage Your Busy Mind.'

She recommends beginning the relaxation therapy with a breathing exercise and then moving from the feet up. She suggests the following exercises:

\section{Feet}

1. Bring your attention to your feet.

2. Point your feet downward, and curl your toes under.

3. Tighten your toe muscles gently, but don't strain.

4. Notice the tension for a few moments, then release, and notice the relaxation. Repeat.

5. Become aware of the difference between the muscles when they are tensed and when they are relaxed.

6. Continue to tense and relax the leg muscles from the foot to the abdominal area.

\section{Abdomen}

1. Gently tighten the muscles of your abdomen, but do not strain.

2. Notice the tension for a few moments. Then release, and notice the relaxation. Repeat.

3. Become aware of the difference between the tensed muscles and relaxed muscles.

\section{Shoulders and neck}

1. Very gently shrug your shoulders straight up towards your ears. Do not strain.

2. Feel the tension for a few moments, release, and then feel the relaxation. Repeat.

3. Notice the difference between the tensed muscles and the relaxed muscles.

4. Focus on the neck muscles, first tensing and then relaxing until you feel total relaxation in this area.

\section{What do I need to do?}

- Gently breathe in - hold - and let go. 


\section{ARTICLES}

- Gently pull your toes up towards your knees - just a little - hold briefly - and let go.

- Recognise the difference. Press your heels into the floor - hold - and let go.

- Pull your knees together - hold briefly - now let them drift apart a little. Be aware of the new position.

- Squeeze your buttocks together - hold - now let go.

- Gently pull in your tummy muscles towards your spine - hold briefly - now let go. Feel the difference.

- Shoulders - gently pull them up towards your ears, just enough to recognise the tension- hold briefly now let go. Recognise the new position.

- Gently press your elbows and upper arms to the sides of your body - hold for a moment - now let go.

- Hands - gently clench - hold - and let go.

- Push your head forward slightly - hold briefly - now let your head go back to a balanced position. Feel the difference.

- Grit your teeth together - hold briefly - now let your jaw sag slightly. Feel the difference.

- Lips - press together - now let go until hardly touching. Purse your lips - now let go and feel the difference.

- Press your tongue briefly to the roof of your mouth - hold - and let it drop loosely. Feel the new position.

- Eyes - screw them up a little - hold - and let go.

- Forehead - frown a little - hold - now let go.

How do I end the relaxation session?

Gradually allow your awareness to expand to become aware of your breathing and of the contact between your body and the floor, bed or chair. When you feel ready, open your eyes, and have a gentle stretch.

\section{REFERENCES}

1. http://projects.hsl.wisc.edu/SERVICE/modules/12/M12_CT_ProgressiveMuscleRelaxation.pdf

2. https://www.guysandstthomas.nhs.uk/resources/patient-information/cardiovascular/jacobsonsprogressive-relaxation-technique.pdf

3. Ms.Palak Patel: A Study to Assess the Effectiveness Of Progressive Muscle Relaxation Therapy on Stress among Staff Nurses Working In Selected Hospitals at Vadodara City (Department Of Mental Health Nursing, Sumandeep Nursing College/ Sumandeep Vidyapeeth University, India) , IOSR Journal of Nursing and Health Science (IOSRJNHS) e-ISSN: 2320-1959.p- ISSN: 2320-1940 Volume 3, Issue 3 Ver. II (May-Jun. 2014), PP 34-59 www.iosrjournals.org

4. Anspaugh DJ, et al. (2011). Coping with and managing stress. In Wellness: Concepts and Applications, 8th ed., pp. 307-340. New York: McGraw-Hill.

5. Uzma Ali, Ph.D: The Effectiveness of Relaxation Therapy in the Reduction of Anxiety Related Symptoms; International Journal of Psychological Studies December 2010 Vol. 2, No. 2; ISSN 19187211 E-ISSN 1918-722X 203-208.

6. Freeman L (2009). Meditation. In L Freeman, ed., Mosby's Complementary and Alternative Medicine: A Research-Based Approach, 3rd ed., pp. 158-188. St. Louis: Mosby Elsevier.

7. Freeman L (2009). Relaxation therapy. In Mosby's Complementary and Alternative Medicine: A Research-Based Approach, 3rd ed., pp. 129-157. St. Louis: Mosby Elsevier.

8. P. Rajkumar et al: International Psychogeriatrics, 21:2, 372-378 International Association 2009.Doi:10.1017/S1041610209008527. 